\title{
Propagation and Purification of Chlamydia trachomatis Serovar L2 Transformants and Mutants
}

Robert Faris and Mary M. Weber*

Microbiology and Immunology, University of lowa, Carver College of Medicine, lowa City, U.S.A. *For correspondence: mary-weber@uiowa.edu

[Abstract] Chlamydia trachomatis (C.t.) is an obligate intracellular pathogen that cannot be cultured axenically and must be propagated within eukaryotic host cells. There are at least 15 distinct chlamydial serovariants that belong to 2 major biovars commonly referred to as trachoma and lymphogranuloma venereum (LGV). The invasive chlamydia LGV serovar L2 is the most widely used experimental model for studying C.t. biology and infection and is the only strain with reliable genetic tools available. New techniques to genetically manipulate C.t. L2 have provided opportunities to make mutants using TargeTron and allelic exchange as well as strains overexpressing epitope-tagged proteins, in turn necessitating the regular purification of transformant and mutant clones. Purification of C.t. is a laborintensive exercise and one of the most common reagents classically used in the purification process, Renografin, is no longer commercially available. A similar formulation of diatrizoate meglumine called Gastrografin is readily available and we as well as others have had great success using this in place of Renografin for chlamydial purifications. Here, we provide a detailed general protocol for infection, propagation, purification, and titering of Chlamydia trachomatis serovar L2 with additional notes specifically pertaining to mutants or recombinant DNA carrying clones.

Keywords: Chlamydia, Chlamydia trachomatis, Propagation, Purification, Culture, Cultivation, Obligate intracellular pathogen, Mutants, Transformants, Recombinant, HeLa

[Background] Chlamydia trachomatis (C.t.) is the etiological agent of blinding trachoma and the most prevalent sexually transmitted disease in the world. Chlamydiae are gram-negative obligate intracellular bacteria that have evolved to occupy a niche within the host cytoplasm derived from a modified endocytic vesical called an inclusion. Chlamydia initiates entry into the host cell by binding to the sialic acid moieties of proteins on the host cell surface. The precise mechanisms regulating entry of C.t. into the host cell are poorly understood but several studies have implicated clathrin mediated endocytosis (Hodinka et al., 1988; Wyrick et al., 1989; Majeed and Kihlstrom, 1991), while others have suggested caveola mediated entry is involved (Boleti et al., 1999). C.t. is taken up into the cell within an endocytic vesicle which it heavily modified to form the chlamydial inclusion. Fusion of this compartment with lysosomes is blocked and the bacterium secretes numerous effector proteins that subvert host resources and redirect them to the inclusion to promote chlamydial proliferation. The Chlamydial lifecycle is biphasic, consisting of different infectious and proliferative stages. The infectious but metabolically inactive form is referred to as an elementary body (EB) while the metabolically active but non-infectious form is called the reticulate body (RB) (Figure 1). Chlamydial EB's bind to sialic acid residues on cell surface receptors and through an unknown mechanism induce their uptake by the cell 
into an endocytic vesicle. The inclusion avoids fusion with lysosomes and degradative compartments while trafficking along microtubules to the peri Golgi region. By about $4 \mathrm{~h}$ post-infection, most of the EBs have converted to RBs. Following chlamydial cell division, the RB's undergo asynchronous conversion to EB's. Depending on stress, cellular environment, and nutrient availability the chlamydial replicative cycle takes 48-72 $\mathrm{h}$ to complete and chlamydia exits via host cell lysis or through extrusion. Of note, the EB is the form usually purified (Caldwell et al., 1981) although techniques have been described to purify RBs (Skipp et al., 2016). For C.t. purifications, the EB is most desirable, since it is the stage associated with infectivity.

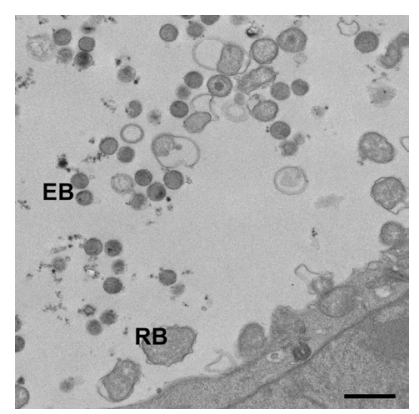

Figure 1. Transmission electron micrograph of wild-type C.t. L2 at $36 \mathrm{~h}$ post-infection. Scale bar is $1 \mu \mathrm{m}$.

Although one study reported that a medium had been developed that could support the axenic metabolic and biosynthetic activity from both EBs and RBs, to the best of our knowledge no lab has had success in using this media to support propagation of chlamydia (Omsland et al., 2012). Thus, in the research laboratory, C.t. is typically cultivated in HeLa 229, Hep2, McCoy, or Vero cells although other cell-types can be used they are less common. Until recently, C.t. was largely intractable to genetic manipulation but advances in tools to generate site-specific mutations and to overexpress proteins during infection have revolutionized the field and labs are now making recombinant $C$.t. clones regularly. In the past, large preparations of C.t. EBs could carry the lab for quite some time. Now, with the generation of new strains occurring on a regular basis, C.t. preparations are a much more common occurrence in the chlamydia laboratory. This is certainly a good thing but cultivating, purifying, and titering new C.t. strains on a regular basis can be a costly and time-consuming endeavor. Not to mention that a key reagent that has been used for years, Renografin, has been made extremely difficult to obtain due to Mallinckrodt ceasing production. Fortunately, a similar product has been identified and new sources discovered (this information will be provided in the materials section). 


\section{Materials and Reagents}

A. Consumables

1. Tissue culture flask T175 (Fisher Scientific, catalog number: 07-000-384)

2. Basix $5 \mathrm{ml}$ serological pipette (Fisher Scientific, catalog number: 14-955-233)

3. Basix $10 \mathrm{ml}$ serological pipette (Fisher Scientific, catalog number: 14-955-234)

4. Basix $25 \mathrm{ml}$ serological pipette (Fisher Scientific, catalog number: 14-955-235)

5. Basix $50 \mathrm{ml}$ conical tube (Fisher Scientific, catalog number: 14-955-239)

6. Beckman $250 \mathrm{ml}$ centrifuge bottle (Fisher Scientific, catalog number: NC9304619)

7. Oak Ridge tube (VWR, catalog number: 76324-812)

8. Thickwall polycarbonate ultracentrifuge tube (Fisher Scientific, catalog number: NC9439275)

9. 18 Gauge Canula (Thomas Scientific, catalog number: 8957G34)

10. $10 \mathrm{ml}$ syringe (Fisher Scientific, catalog number: 14-841-54)

11. $1.5 \mathrm{ml}$ conical screwcap tube (USA Scientific, catalog number: 1415-8700)

12. 24-well plate (Fisher Scientific, catalog number: 07-000-030)

13. N-95 mask

B. Experimental models: cell lines

1. HeLa cells ATCC CCL-2

C. Bacterial strains

1. Chlamydia trachomatis serovar L2 ATCC VR-902B

D. Antibodies

1. Chlamydia trachomatis LPS antibody, mouse monoclonal Novus NBP1-28820

2. Rabbit anti-Mouse IgG $(\mathrm{H}+\mathrm{L})$ Cross-Adsorbed Secondary Antibody, Alexa Fluor 488 (Thermo Fisher, catalog number: A-11059)

E. Chemicals, peptides, recombinant proteins, and miscellaneous reagents

1. Gastrografin (Bracco, catalog number: 0270-0445-40)

2. RPMI 1640 medium with L-glutamine (Thermo Fisher, catalog number: 11875-093)

3. $\mathrm{NaHCO}_{3}$ (Sodium bicarbonate) (Thermo Fisher, catalog number: 25080094)

4. Gentamicin (Thermo Fisher, catalog number: 15710072)

5. Trypsin-EDTA $0.5 \%$ (Thermo Fisher, catalog number: 15400054)

6. Heat-inactivated Fetal Bovine Serum (VWR, catalog number: 89510-186)

7. 1x PBS without calcium chloride and magnesium (Thermo Fisher, catalog number: 10010-049)

8. 1x HBSS without calcium chloride and magnesium (Thermo Fisher, catalog number: 14170112)

9. Cycloheximide (MilliporeSigma, catalog number: C4859-1ML)

10. $\mathrm{KH}_{2} \mathrm{PO}_{4}$ (Fisher Scientific, catalog number: P285-500) 
11. $\mathrm{K}_{2} \mathrm{HPO}_{4}$ (Fisher Scientific, catalog number: P288-500)

12. $\mathrm{KCl}$ (Fisher Scientific, catalog number: P217-500)

13. $\mathrm{NaCl}$ (Fisher Scientific, catalog number: S271-500)

14. L-Glutamic Acid (Fisher Scientific, catalog number: A125-100)

15. DEAE Dextran (MP Biomedicals, catalog number: ICN19513380)

16. Methanol (Fisher Scientific, catalog number: A412-500)

17. Sucrose

18. $\mathrm{Na}_{2} \mathrm{HPO}_{4}$ (Sodium phosphate dibasic anhydrous)

19. $\mathrm{NaH}_{2} \mathrm{PO}_{4} \cdot \mathrm{H}_{2} \mathrm{O}$ (Sodium phosphate monobasic monohydrate)

20. Blood agar plate

21. Yeast peptone dextrose (YPD) agar plate

22. $10 \times \mathrm{K} 36$ (see Recipes)

23. $1 \times$ K36 (see Recipes)

24. Sucrose Phosphate Glutamate buffer (SPG) (see Recipes)

25. 30\% Gastrografin (see Recipes)

26. $54 \%$ Gastrografin (see Recipes)

27. $44 \%$ Gastrografin (see Recipes)

28. $40 \%$ Gastrografin (see Recipes)

29. 10x DEAE dextran (see Recipes)

30. 1x DEAE dextran (see Recipes)

\section{Equipment}

1. P200 Pipette

2. Shaker

3. Humidified $\mathrm{CO}_{2}$ cell culture incubator set to $37^{\circ} \mathrm{C}$

4. Floor Centrifuge Avanti JXN-30 (Beckman, catalog number: B38624)

5. Rotor: JLA-16.250 (Beckman, catalog number: 363934)

6. Rotor: JLA-25.50 (Beckman, catalog number: 363058)

7. Rotor: JS-24.15 (Beckman, catalog number: 362396)

8. Table top Centrifuge Allegra X-14R (Beckman, catalog number: A99465)

9. Microcentrifuge Microfuge20R (Beckman, catalog number: B31599)

10. Sonicator Q-sonica Q500 (VWR, catalog number: 89207-036)

11. Sonicator Probe CL-334 (VWR, catalog number: 89207-036)

12. Fluorescent microscope

13. Biosafety cabinet

14. $-80{ }^{\circ} \mathrm{C}$ freezer

15. Large cell scraper (Fisher Scientific, catalog number: 08-100-241) 


\section{Procedure}

Note: As Chlamydia trachomatis is a BSL2 pathogen, all steps must be carried out in a biosafety cabinet (BSC). Ensure all solutions are sterile prior to beginning the purification.

\section{A. Seeding and preparing HeLa Cells}

1. Seed 8 T175 flasks with early passage HeLa cells $(<P 10)$ at a cell concentration sufficient to reach confluency in 1-2 days.

Note: We have propagated C.t. in immortalized primary epithelial cells of several lineages (vaginal, cervical, conjunctival, foreskin), but have not carried out large scale purifications from these cells lines, primarily due to the exorbitant cost of the reagents needed to propagate these cells. Theoretically, the purifications would proceed identical to what we describe in this protocol with the only changes being the media for each respective cell type.

2. Decant the media from 8 T175 flasks of confluent HeLa cells.

3. Gently wash the cells using $5 \mathrm{ml}$ of $1 \times$ Phosphate Buffer Saline (PBS) per flask. Ensure most of the wash is removed using a $5 \mathrm{ml}$ serological pipette.

4. Add $5 \mathrm{ml}$ Trypsin to each flask, gently swirl to ensure it covers the entire bottom of the flask, and incubate cells at $37^{\circ} \mathrm{C}$ for $5-10$ min or until cells detach.

5. Add $5 \mathrm{ml}$ RPMI 1640 with $10 \%$ FBS to each flask. Combine cells from 8 flasks into 1 flask.

6. Prepare 20 new T175 flasks by adding $30 \mathrm{ml}$ RPMI 1640 with $10 \%$ FBS.

7. Add $4 \mathrm{ml}$ diluted cell mixture (Step A4) to each new flask. Seed enough cells to obtain confluency $\left(1 \times 10^{7} /\right.$ flask $)$.

8. Incubate cells at $37{ }^{\circ} \mathrm{C}$ with $5 \% \mathrm{CO}_{2}$ for $24 \mathrm{~h}$ or until HeLa monolayers are confluent.

B. Infection (20 Flask Batch)

1. Remove aliquot of Chlamydia trachomatis $\mathrm{L} 2$ from $-80{ }^{\circ} \mathrm{C}$ freezer and let thaw at room temperature. Prepare Chlamydia trachomatis inoculum in $5 \mathrm{ml}$ RPMI 1640 with 10\% FBS and $10 \mu \mathrm{g} / \mathrm{ml}$ cycloheximide using a Multiplicity of Infection (MOI) 2.5 assuming $2 \times 10^{7}$ cells/flask at confluency. Use $100 \mathrm{ml}$ total for 20 flasks.

Note: For mutants with a lysis or toxic phenotype, reduce MOI to 0.5. Include any relevant antibiotic for mutant selection in the RPMI 1640.

2. Decant the media from each flask.

3. Add $5 \mathrm{ml}$ of inoculum from Step $\mathrm{B} 1$ to each flask and incubate at $37{ }^{\circ} \mathrm{C}$ with slow shaking or rocking for $30 \mathrm{~min}-1 \mathrm{~h}$.

4. Add $25 \mathrm{ml} \mathrm{RPMl} 1640$ with $10 \% \mathrm{FBS}$ and $10 \mu \mathrm{g} / \mathrm{ml}$ cycloheximide to each flask. Note: Cycloheximide prevents host cell synthesis to facilitate bacterial replication

5. Incubate for $36-48 \mathrm{~h}$ at $37^{\circ} \mathrm{C}$ with $5 \% \mathrm{CO}_{2}$.

C. Purification

1. Decant the media from each of the 20 flasks. 
2. Add $8 \mathrm{ml}$ ice-cold $1 \times \mathrm{K} 36$ (Recipe 2 ) to each of the 20 flasks.

3. Scrape each flask using a large cell scraper. Rinse the back of each flask with the $1 \times$ K36-cell mix and transfer cell suspension from 10 flasks to a $250 \mathrm{ml}$ centrifuge bottle on ice. Repeat for the next 10 flasks with another $250 \mathrm{ml}$ centrifuge bottle.

Note: The cell suspension from 10 flasks should be added to each of two $250 \mathrm{ml}$ centrifuge bottles. Splitting the 20 flasks of cell suspension into two $250 \mathrm{ml}$ centrifuge bottles will provide adequate space for mixing and a balance for all centrifugation steps moving forward. A total of four $250 \mathrm{ml}$ centrifuge bottles will be needed for the entire purification. Two $250 \mathrm{ml}$ centrifuge bottles will be used through Step C6 and two will be used starting on Step C7.

4. Rinse the back of the $\mathrm{T} 175$ flask with $5 \mathrm{ml} \mathrm{K36}$, transfer to another T175 flask. Continue to rinse and transfer for 5 flasks in total. After washing the $5^{\text {th }}$ flask, add the cell suspension to the $250 \mathrm{ml}$ centrifuge bottle on ice. Discard the first 5 T175 flasks. Repeat procedure with remaining flasks.

5. Sonicate at $60-100$ watts for $20 \mathrm{~s}$, immediately return centrifuge bottle to ice. Repeat sonication step for two sonication cycles total per $250 \mathrm{ml}$ centrifuge bottle

Note: An N-95 mask should be worn during the sonication and sonication should be conducted in the BSC.

6. Centrifuge at $500 \times g$ for $10 \mathrm{~min}$ at $4{ }^{\circ} \mathrm{C}$.

7. Transfer each supernatant to a new pre-chilled $250 \mathrm{ml}$ centrifuge bottle on ice.

8. Resuspend each pellet in $100 \mathrm{ml}$ ice-cold $1 \times \mathrm{K} 36$.

9. Sonicate at $60-100$ watts for $20 \mathrm{~s}$, immediately return centrifuge bottle to ice. Repeat sonication step for two cycles in total per $250 \mathrm{ml}$ centrifuge bottle.

10. Centrifuge at $500 \times g 10 \mathrm{~min}$ at $4{ }^{\circ} \mathrm{C}$.

11. Add supernatant to the pre-chilled $250 \mathrm{ml}$ centrifuge bottles from Step C7.

12. Centrifuge at $30,000 \times g$ for 20 min at $4{ }^{\circ} \mathrm{C}$.

13. Remove the supernatant from each $250 \mathrm{ml}$ centrifuge bottle (there are 2 ) and resuspend each pellet with $30 \mathrm{ml} 1 \times \mathrm{K} 36$. Disperse using an $18 \mathrm{ga}$ cannula on a $10 \mathrm{ml}$ syringe. Solution should be slowly dispersed to prevent frothing and should be passed 3-5 times or until the solution is homogenous.

14. Add $8 \mathrm{ml}$ of $30 \%$ Gastrografin (Recipe 4 ) to a thick-walled polycarbonate ultracentrifuge tube. Note: Diatrizoate meglumine and diatrizoate sodium solutions allow for optimal density gradient isolation of chlamydial elementary bodies with minimal host debris and negligible loss of bacteria or toxicity. They are normally used as contrasting agents in radiography due to the iodine content.

15. Gently layer the suspension from Step C13 over the Gastrografin. Top the tubes with 1x K36.

16. Centrifuge at $40,000 \times g$ for $30 \mathrm{~min}$ at $4{ }^{\circ} \mathrm{C}$.

17. Decant supernatant and resuspend pellet in $1 \times$ K36 using $1 \mathrm{ml}$ per T175 flask (10 ml per pellet for a 20 -flask prep). 
Note: To prepare $30 \%$ seed stock instead of doing the full purification, resuspend pellet in SPG (Recipe 3). Transfer to an oak ridge tube, and centrifuge at 30,000 x g for $20 \mathrm{~min}$ at $4{ }^{\circ} \mathrm{C}$. Resuspend pellet in $5 \mathrm{ml}$ ice-cold SPG, aliquot and store at $-80^{\circ} \mathrm{C}$.

18. Prepare Gastrografin density gradient by very slowly layering the following in order into a thick-

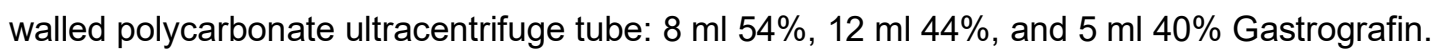

19. Gently add the suspension from Step C17 to the gradient and top with K36.

20. Centrifuge at $40,000 \times g$ for $60 \mathrm{~min}$ at $4{ }^{\circ} \mathrm{C}$.

21. Collect the white elementary body band between the two lower layers ( $54 \%$ and $44 \%$ ) using a cannula and transfer it to a pre-chilled oak ridge tube on ice (Figure 2A).

22. Add approximately 10 volumes of ice-cold SPG.

23. Centrifuge at $30,000 \times \mathrm{g}$ for $20 \mathrm{~min}$ at $4^{\circ} \mathrm{C}$. Resuspend pellet in $1 \mathrm{ml} / \mathrm{flask}$ of SPG. Use a cannula to disperse if necessary. Aliquot (50-100 $\mu$ l) into sterile O-ring tubes using a P200 pipette and store at $-80^{\circ} \mathrm{C}$.

24. Test sterility by inoculating a blood agar plate, yeast peptone dextrose (YPD) agar plate, and RPMI 1640 media with $10 \mu$ l of purified EBs.

D. Titers

1. Seeding HeLa Cells for titer plates

a. Decant the media from T175 flask of confluent HeLa cells.

b. Gently wash the cells using $5 \mathrm{ml}$ of $1 \times$ PBS per flask. Ensure most of the wash is removed using a serological pipette.

c. Add $5 \mathrm{ml}$ Trypsin to each flask, gently swirl to distribute along the back of the flask, and incubate cells at $37^{\circ} \mathrm{C}$ for $5-10$ min or until cells detach.

d. Add 5 ml RPMl 1640 with $10 \%$ FBS to flask.

e. Add $1 \mathrm{ml}$ of cells to $20 \mathrm{ml}$ of RPMl 1640 with $10 \%$ FBS.

f. Add $1 \mathrm{ml}$ of diluted cell mixture to each well of a 24-well plate. Cells should be seeded to obtain $1 \times 10^{5}$ per well.

g. Incubate the cells at $37^{\circ} \mathrm{C}$ with $5 \% \mathrm{CO}_{2}$ for $24 \mathrm{~h}$. The cells should be confluent.

2. Infect cells

a. Thaw an aliquot of purified EBs.

b. Add $30 \mu \mathrm{l}$ EBs to $270 \mu \mathrm{l} 1 \mathrm{x}$ Hanks buffered saline solution (HBSS). Vortex to mix.

c. Serially dilute $1: 10$ in $1 \times$ HBSS.

d. Remove media from the 24-well plate using a serological pipette.

e. Add $200 \mu \mathrm{l}$ of each dilution in triplicate to 3 wells of the 24-well plate.

f. Add $1 \mathrm{ml} \mathrm{RPMl} 1640$ with $10 \% \mathrm{FBS}$ and $10 \mu \mathrm{g} / \mathrm{ml}$ cycloheximide. Incubate at $37^{\circ} \mathrm{C}$ with $5 \%$ $\mathrm{CO}_{2}$ for $\sim 24 \mathrm{~h}$.

Note: For wild-type C. trachomatis $L 2$ prepared using this protocol we obtain a titer of $\sim 10 \% / \mathrm{ml}$. Thus, we plate the $10^{4}, 10^{5}$, and $10^{6}$ dilutions. Depending on the efficiency of the purifications the plating dilutions may need to be lower or higher. 
3. Determine titer

a. Remove media from the 24-well plate using a serological pipette.

b. Wash each well with $0.5 \mathrm{ml} 1 \times$ PBS twice.

c. Add $0.5 \mathrm{ml}$ methanol to each well and incubate at room temperature for $20 \mathrm{~min}$.

d. Remove methanol and discard in methanol waste container.

e. Wash each well with $0.5 \mathrm{ml} 1 \times$ PBS twice.

f. Add $0.25 \mathrm{ml}$ of anti-LPS diluted 1:1,000 in 1x PBS. Incubate on a shaker at $70 \mathrm{rpm}$ for $\sim 1 \mathrm{~h}$ at room temperature.

g. Wash each well with $0.5 \mathrm{ml} 1 \times$ PBS three times.

h. Add $0.25 \mathrm{ml}$ of anti-mouse 488 diluted 1:1,000 in 1x PBS. Incubate on a shaker at $70 \mathrm{rpm}$ for $\sim 1 \mathrm{~h}$ at room temperature.

i. Wash each well with $0.5 \mathrm{ml} 1 \times$ PBS three times.

j. Leave $0.5 \mathrm{ml} 1 \times$ PBS in each well after the final wash. Note: Plate can be stored at $4{ }^{\circ} \mathrm{C}$ till counts are complete.

k. Count 10 fields of view per well using 20x object on fluorescent microscope (Figure 2B).

A.

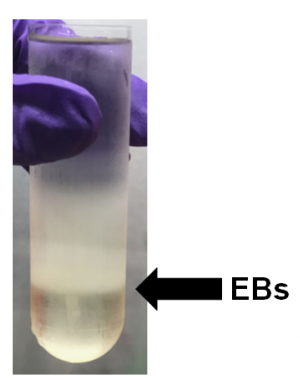

B.

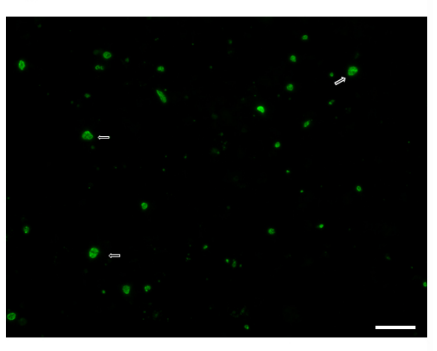

Figure 2. Density gradient purification of EBs. A. Gradient purification of C.t. L2. Black arrow denotes the location of EBs at the $54 \%$ and $44 \%$ interface. B. Immunofluorescence of chlamydia titer plates. C.t. was stained using anti-LPS (green) and the white arrow denotes examples of the chlamydia inclusions. Scale bar is $50 \mu \mathrm{m}$.

\section{Data analysis}

Determine the titer using the following equation:

Titer $=(X / 10) \times 196 \times 5 \times D$

where,

$X$ is the total number of inclusions from the 10 fields counted;

196 is the number of fields of view on a 24-well plate using a 20x objective;

5 is the fraction of a ml plated;

$\mathrm{D}$ is the dilution factor counted; 
Example: If 232 inclusions were observed in 10 fields of view using a sample diluted $10^{4}$. The titer is $(232 / 10) \times 196 \times 5 \times 10,000=2.27 \times 10^{8}$.

\section{$\underline{\text { Notes }}$}

1. This protocol involves purification of $\mathrm{L} 2 \mathrm{EBs}$, however $\mathrm{EBs}$ from other $C$. trachomatis serovars can be accomplished using this protocol with a few minor modifications (Table 1) regarding the length of time from infection to harvest and pretreatment with DEAE-dextran (Sabet et al., 1984). Cells are pretreated prior to infection by adding $5 \mathrm{ml} 1 \times$ DEAE-dextran to each flask and are incubated at $37^{\circ} \mathrm{C}$ for $30 \mathrm{~min}$. The dextran is removed and cells are ready to be infected.

2. A common question for this procedure is how $E B$ s are separated from RBs during the purification. Sonication is sufficient to lyse RBs along with the host cell while leaving EBs intact. All debris is then separated from the relatively dense EBs via gradient centrifugation.

3. Purification of chlamydia must be carried out in a Biosafety Level 2 laboratory.

Table 1. Purification guidelines for Chlamydia trachomatis serovars

\begin{tabular}{|c|c|c|c|c|}
\hline Serovar & MOI & DEAE pretreatment & Cycloheximide & Growth until harvest \\
\hline $\bar{A}$ & 1 & Yes & Yes & $70-72 \mathrm{~h}$ \\
\hline B & 0.5 & Yes & Yes & $70-72 \mathrm{~h}$ \\
\hline B Jali 20 & 1 & Yes & Yes & $70-72 \mathrm{~h}$ \\
\hline B Har36 & 1 & Yes & Yes & $70-72 \mathrm{~h}$ \\
\hline $\mathrm{Ba}$ & 1 & Yes & Yes & $70-72 \mathrm{~h}$ \\
\hline C & 1 & Yes & Yes & $70-72 \mathrm{~h}$ \\
\hline D & 0.5 & Yes & Yes & $62-66 \mathrm{~h}$ \\
\hline$E$ & 1 & Yes & Yes & $46-48 \mathrm{~h}$ \\
\hline$F$ & 1 & Yes & Yes & $46-48 \mathrm{~h}$ \\
\hline G & 1 & Yes & Yes & $70-72 \mathrm{~h}$ \\
\hline $\mathrm{H}$ & 1 & Yes & Yes & $70-72 \mathrm{~h}$ \\
\hline I & 1 & Yes & Yes & $70-72 \mathrm{~h}$ \\
\hline J & 1 & Yes & Yes & $70-72 \mathrm{~h}$ \\
\hline K & 1 & Yes & Yes & $70-72 \mathrm{~h}$ \\
\hline $\mathrm{L}_{1}$ & 1 & No & Improves titer & $46-48 \mathrm{~h}$ \\
\hline $\mathrm{L}_{2}$ & $3-5$ & No & Improves titer & $46-48 \mathrm{~h}$ \\
\hline $\mathrm{L}_{3}$ & 1 & No & Improves titer & $46-48 \mathrm{~h}$ \\
\hline
\end{tabular}

\section{$\underline{\text { Recipes }}$}

1. $10 \times \mathrm{K} 36$

a. Dissolve $68 \mathrm{~g}$ Potassium phosphate monobasic (500 mM KH $2 \mathrm{PO}_{4}$ ), $87.1 \mathrm{~g}$ potassium phosphate dibasic (500 mM K2 $\mathrm{HPO} 4), 74.5 \mathrm{~g}$ potassium chloride $(1 \mathrm{M} \mathrm{KCl}), 8.7 \mathrm{~g}$ sodium chloride $(150 \mathrm{mM} \mathrm{NaCl})$ in $900 \mathrm{ml}$ distilled water. Adjust to $\mathrm{pH} 7.0$ with $1 \mathrm{~N} \mathrm{KOH}$ 
b. Adjust volume to $1 \mathrm{~L}$ using a graduated cylinder

c. Aliquot in $100 \mathrm{ml}$ sterile bottles

d. Autoclave and store at $4{ }^{\circ} \mathrm{C}$

2. $1 \times \mathrm{K} 36$

Add $100 \mathrm{ml} 10 \times \mathrm{K} 36$ to $900 \mathrm{ml}$ sterile distilled water, store at $4{ }^{\circ} \mathrm{C}$

3. Sucrose Phosphate Glutamate buffer (SPG)

a. Dissolve $3.75 \mathrm{~g}$ sucrose (10 mM), $2.47 \mathrm{~g}$ sodium phosphate dibasic anhydrous (17.4 mM $\left.\mathrm{Na}_{2} \mathrm{HPO}_{4}\right), 0.36 \mathrm{~g}$ sodium phosphate monobasic monohydrate $\left(2.5 \mathrm{mM} \mathrm{NaH}_{2} \mathrm{PO}_{4} \cdot \mathrm{H}_{2} \mathrm{O}\right)$ and $0.72 \mathrm{~g} \mathrm{~L}-$ Glutamic Acid in $900 \mathrm{ml}$ distilled water. Adjust to $\mathrm{pH} 7.4$ with either $1 \mathrm{~N} \mathrm{HCl}$ or $1 \mathrm{~N}$ $\mathrm{KOH}$ as needed. The $\mathrm{pH}$ should be very close to 7.4 already

b. Using a graduated cylinder, adjust the volume to $1 \mathrm{~L}$

c. Filter sterilize and store at $4{ }^{\circ} \mathrm{C}$

4. $30 \%$ Gastrografin

$30 \mathrm{ml}$ Gastrografin

$70 \mathrm{ml} 1 \mathrm{x} \mathrm{K36}$

5. $54 \%$ Gastrografin

$54 \mathrm{ml}$ Gastrografin

$46 \mathrm{ml}$ 1x K36

6. $44 \%$ Gastrografin

$44 \mathrm{ml}$ Gastrografin

$66 \mathrm{ml} 1 \times \mathrm{K} 36$

7. $40 \%$ Gastrografin

$40 \mathrm{ml}$ Gastrografin

$60 \mathrm{ml} 1 \times \mathrm{K} 36$

8. 10x DEAE dextran

Dissolve $450 \mu \mathrm{g} / \mathrm{ml}$ of DEAE-dextran in $100 \mathrm{ml}$ distilled water to prepare $10 \mathrm{x}$ stock

9. 1x DEAE dextran

a. Add $10 \mathrm{ml} \mathrm{10x} \mathrm{Hanks} \mathrm{Buffered} \mathrm{Saline} \mathrm{Solution} \mathrm{(HBSS)} \mathrm{and} 10 \mathrm{ml}$ 10x DEAE-dextran to 80 $\mathrm{ml}$ distilled water

b. Adjust to $\mathrm{pH} 7.4$ using $7.5 \% \mathrm{NaHCO}_{3}$

c. Filter sterilize solution and store at room temperature

\section{Acknowledgments}

This research was supported by startup funds from the University of lowa Department of Microbiology and Immunology to M.M.W. This protocol was adapted from Caldwell et al., 1981. 


\section{Competing interests}

The authors have no conflict of interest to declare.

\section{$\underline{\text { References }}$}

1. Boleti, H., Benmerah, A., Ojcius, D. M., Cerf-Bensussan, N. and Dautry-Varsat, A. (1999). Chlamydia infection of epithelial cells expressing dynamin and Eps15 mutants: clathrinindependent entry into cells and dynamin-dependent productive growth. J Cell Sci 112 (Pt 10): 1487-1496.

2. Caldwell, H. D., Kromhout, J. and Schachter, J. (1981). Purification and partial characterization of the major outer membrane protein of Chlamydia trachomatis. Infect Immun 31(3): 1161-1176.

3. Hodinka, R. L., Davis, C. H., Choong, J. and Wyrick, P. B. (1988). Ultrastructural study of endocytosis of Chlamydia trachomatis by McCoy cells. Infect Immun 56(6): 1456-1463.

4. Majeed, M. and Kihlström, E. (1991). Mobilization of F-actin and clathrin during redistribution of Chlamydia trachomatis to an intracellular site in eucaryotic cells. Infect Immun 59(12): 44654472.

5. Omsland, A., Sager, J., Nair, V., Sturdevant, D. E. and Hackstadt, T. (2012). Developmental stage-specific metabolic and transcriptional activity of Chlamydia trachomatis in an axenic medium. Proc Natl Acad Sci U S A 109(48): 19781-19785.

6. Skipp, P. J., Hughes, C., McKenna, T., Edwards, R., Langridge, J., Thomson, N. R. and Clarke, I. N. (2016). Quantitative proteomics of the infectious and replicative forms of Chlamydia trachomatis. PLoS One 11(2): e0149011.

7. Wyrick, P. B., Choong, J., Davis, C. H., Knight, S. T., Royal, M. O., Maslow, A. S. and Bagnell, C. R. (1989). Entry of genital Chlamydia trachomatis into polarized human epithelial cells. Infect Immun 57(8): 2378-2389. 